\title{
CORRIGENDUM
}

\section{Phonon-cavity electromechanics}

I. Mahboob, K. Nishiguchi, H. Okamoto and H. Yamaguchi

Nature Physics http://dx.doi.org/10.1038/nphys2277 (2012); published online 1 April 2012; corrected after print 26 April 2012.

In the version of this Letter originally published, the name of the first author of ref. 21 should have read 'De Liberato, S.. This error has been corrected in the HTML and PDF versions of the Letter. 